\title{
Antibacterial Activity of Certain Ferns Against Multi Drug Resistant Organisms
}

\author{
Kathakali Nath ${ }^{1}$, Anupam Das Talukdar' ${ }^{2}$, Mrinal Kanti Bhattacharya ${ }^{3 *}$, Deeshikha Bhowmik', \\ Shiela Chetri ${ }^{1}$, Debarati Choudhury ${ }^{2}$, Abhijit Mitra ${ }^{2}$ and Amitabha Bhattacharjee ${ }^{1}$ \\ 1Department of Microbiology, Assam University, Silchar - 788011, Assam, India \\ 2Department of Life Science and Bio informatics, Assam University, Silchar - 788011, Assam, India \\ ${ }^{3}$ Department of Botany and Biotechnology, Karimganj College, Karimganj - 788710, Assam, India
}

\begin{abstract}
Antibacterial activity of frond extracts of three ethno medicinal important ferns viz. Angiopteris helferiana C. Presl, Cyathea brunoniana (Wall. ex Hook.) C.B. Clarke \& Baker and Pronephrium nudatum (Roxb. ex Griff) Holttum was assayed by well diffusion method against multi drug resistant organisms i.e., Escherichia coli, Pseudomonas aeruginosa and Staphylococcus aureus. The result revealed that the ethyl acetate frond extract of Cyathea brunoniana, Pronephrium nudatum were active against methicillin resistant Staphylococcus aureus while that of Angiopteris helferiana was active against only Staphylococcus aureus (ATCC 25923). The minimum inhibitory concentration of crude ethyl acetate frond extract of Cyathea brunoniana, Pronephrium nudatum was found to be $400 \mathrm{mg} / \mathrm{ml}$ against methicillin resistant Staphylococcus aureus. The synergistic activity of the crude extract with the antibiotics showed that the antibacterial activity of the antibiotics increased in synergy with crude extract of Cyathea brunoniana and Pronephrium nudatum respectively. Thereby, the results indicated the possibility of using the fern extract of Cyathea brunoniana and Pronephrium nudatum as a future treatment option against methicillin resistant Staphylococcus aureus.
\end{abstract}

Keywords: Fern, Ethno-Medicine, Methicillin Resistant, Staphylococcus aureus

\section{Introduction}

The effectiveness of conventional and current drugs is getting limited due to the rapid development of resistance by the pathogenic bacteria which often leads to treatment failure and subsequently leaving the clinicians with fewer antibiotics ${ }^{1}$. This increasing resistance to antibiotics has thus necessitated the need to search for new antibacterial agents. Staphylococcus aureus responsible for various post-operative infections, endocarditis etc. which was once easily treatable, but in the recent years emerged out to be resistant against methicillin drug and still emerging resistance against vancomycin. Gram negative bacterium such as Escherichia coli is a normal flora in human intestine but can cause lower urinary tract infection, coleocystis or septicaemia ${ }^{2}$. The development of antibiotic resistance is multifactorial, including spontaneous mutation, DNA transfer or by human activities. This

\footnotetext{
${ }^{*}$ Author for correspondence
} 
resistance problem demands that a renewed effort has to be made to screen various medicinal plants for their potential antimicrobial traits, which are due to compounds synthesised during the secondary metabolism by the plant. The most important of these bioactive compounds of plants are alkaloids, flavanoids, tannins, phenolic compounds ${ }^{3}$.

Pteridophytes forms an important part of the Indian flora, representing about $10 \%$ of the world pteridophytic flora ${ }^{4}$. The pretidophytes are of emmense ethno-medicinal importance and are used by ethnic people ${ }^{5}$. The medicinal importance of pteridophytes are well-studied by many authors from different parts of the country ${ }^{6-8}$. The leaf extract of Angiopteris helferiana C. Presl is used in the treatment of dysentery and diseases of blood ulcers. Spores are also effective in leprosy and skin diseases ${ }^{9}$, the apical part of caudex is especially used against carbuncle and the rhizome paste is applied externally to cure broken or fractured bones ${ }^{10}$. Paste of soft apical portion of the caudex of Cyathea brunoniana (Wall. ex Hook.) C.B. Clarke \& Baker is applied locally on major cuts and wounds to prevent microbial growth so that no abscess could form and the same also causes immediate blood clotting ${ }^{10,11}$. The phytochemical analysis of caudex and leaves of Cyathea brunoniana showed the presence of flavonoid and steroid in petroleum ether, ethyl acetate, acetone and methanol extract, while saponin was present in ethyl acetate caudex extract and all the leaves' extract ${ }^{12}$. Cold decoction of pinnae of Pronephrium nudatum (Roxb. ex Griff) Holttum is used as mouth wash during acute pyorrhoea ${ }^{10}$.
This research was designed to study the antibacterial activity of three ethno-medicinally important ferns for their antibacterial property against multi drug resistant organisms i.e., Escherichia coli, Pseudomonas aeruginosa and Staphylococcus aureus. Moreover, determination of minimum inhibitory concentration of the crude extract and synergy of the crude extract with the conventional antibiotics was also carried out.

\section{Methodology}

\subsection{Plant Material}

Fresh plant material (fronds) of Angiopteris helferiana, Cyathea brunoniana andPronephrium nudatum were collected from Southern Assam.

\subsection{Extract Preparation}

The leaf samples were washed thoroughly 23 times with running tap water and once with sterile water, airdried, powdered and used for extraction. Fifty grams of each of the airdried and coarsely powdered plant material was extracted successively with 500 $\mathrm{ml}$ each of ethyl acetate, methanol and water in the increasing order of their polarity using a soxhlet evaporator ${ }^{13}$. Water extract was prepared by boiling (3-4 hours) in a hot water bath.

\subsection{Micro-Organisms}

Phenotypically characterised metallo betalactamase, extended spectrum beta-lactamase producing Escherichia coli and Pseudomonas aeruginosa respectively, and methicillin resistant Staphylococcus aureus were obtained from the 
Department of Microbiology, Silchar Medical College and Hospital, Silchar. Three reference strains from American Type Culture Collection were used, viz. Escherichia coli ATCC 25922, Staphylococcus aureus ATCC 25923 and Pseudomonas aeruginosa PAO1.

\subsection{Antibacterial Activity of Fern Extract}

Antibacterial activity of aqueous and solvent extracts was determined by agar well diffusion method. Inoculum containing $105 \mathrm{cfu} / \mathrm{ml}(0.5 \mathrm{Mc}$ Farland Standard) of each bacterial culture to be tested was spread on Mueller Hinton agar plates with a sterile swab moistened with the bacterial suspension. Subsequently, wells of $5 \mathrm{~mm}$ diameter were punched into the agar medium and filled with $20 \mu \mathrm{l}$ of plant extract. The plates were then incubated in the upright position at $37^{\circ} \mathrm{C}$ for $24 \mathrm{~h}$. Wells containing the same volume of DMSO served as negative controls while standard antibiotic discs of ampicillin $(10 \mu \mathrm{g})$ and ciprofloxacin $(5 \mu \mathrm{g})$ were used as the positive controls. After incubation, the diameters of the inhibition zones were measured in $\mathrm{mm} 3$.

\subsection{Minimum Inhibitory Concentration}

The MIC of the extracts was performed by broth dilution method. Various dilutions of the extract i.e., $400-25 \mathrm{mg} / \mathrm{ml}$ were prepared in DMSO (Dimethyl Sulphoxide) into sets of test tubes with the culture media. $50 \mu \mathrm{l}$ of the bacterial broth culture (after matching the turbidity with 0.5 McFarland standard) was added into each of the test tubes. The bacterial cultures containing the plant extracts were incubated at $37^{\circ} \mathrm{C}$ for 24 hours. Test tube containing only the growth medium and each of the organisms were also incubated under the same conditions as positive controls. The minimum inhibitory concentration was expressed as the lowest concentration of the extracts that did not permit any visible growth when compared to that of the control tubes ${ }^{14}$.

\subsection{Minimum Bactericidal Concentration of Fern Extract}

Samples from the tubes used in the MIC assays, which did not show any visible growth after a period of incubation were sub-cultured onto a freshly prepared nutrient medium ${ }^{15}$. The minimum bactericidal concentration was taken as the lowest concentration of the extract that did not yield a single colony on the nutrient agar plate after 24 hours incubation period.

\subsection{Synergism of Crude Extract with Conventional Antibiotics}

A bacterial suspension was prepared and was standardized to give a resultant concentration of $1 \mathrm{x} 10^{8} \mathrm{cfu} / \mathrm{ml}$. Bacteria was then seeded onto Mueller Hinton agar plates by swabbing with a sterile swab. To the seeded plates antibiotic disc were placed and $6 \mu \mathrm{l}$ of the plant extract was added on the antibiotic disc. The same method was repeated for antibiotic disc alone and the plant extract alone. Then the plates were allowed to stand for 30 minutes and incubated at $37^{\circ} \mathrm{C}$ for 24 hours. The determinations were carried out in triplicates. The diameter of the zone of inhibition by the extract alone, antibiotic disc alone and their combinations were measured 
Table 1: Antibacterial activity of frond extract of three ethno-medicinal ferns

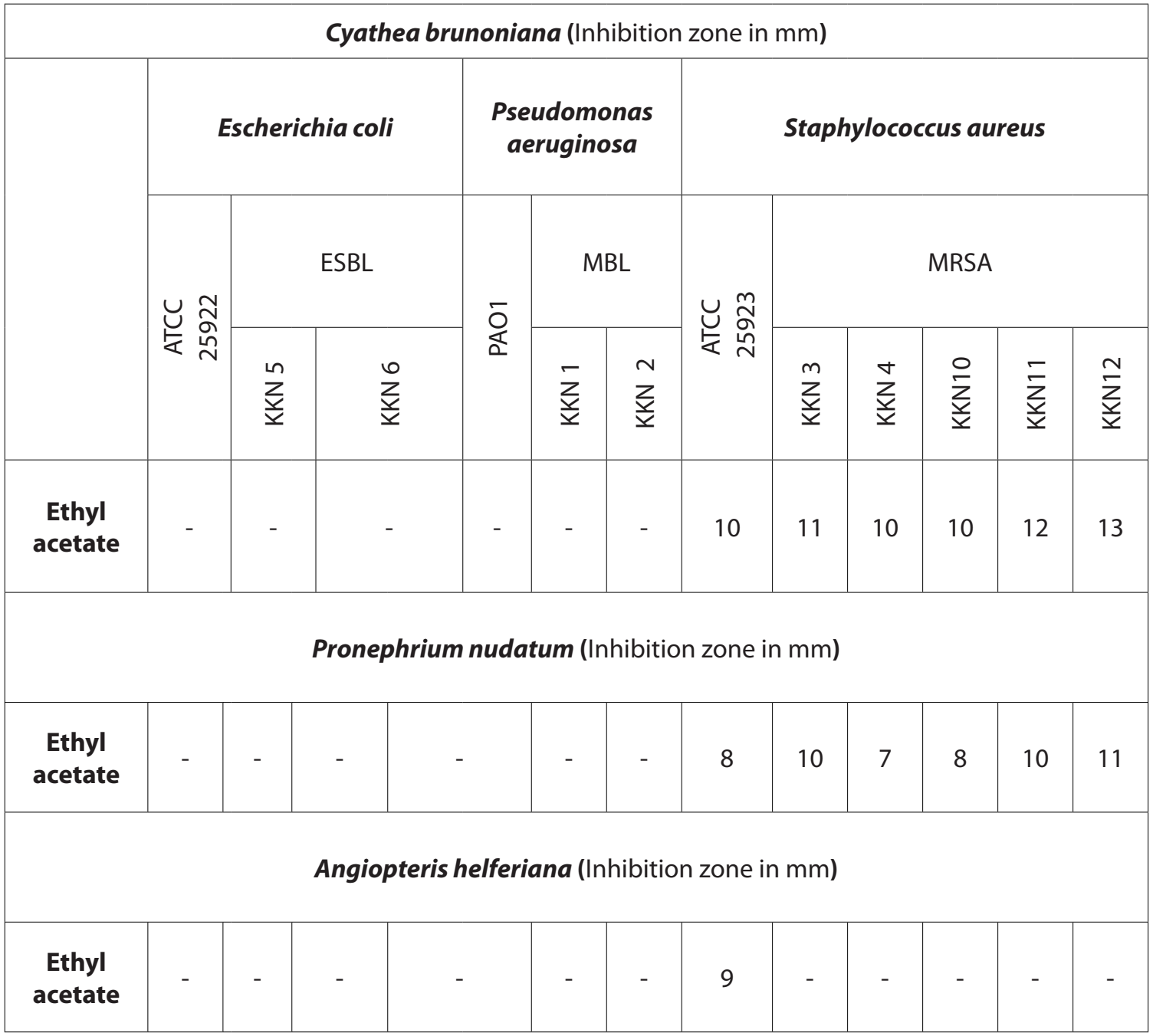

$=$ No zone of inhibition; ESBL $=$ Extended spectrum beta-lactamase; $\mathrm{MBL}=$ Metallo beta-lactamase; MRSA = Methicillin resistant Staphylococcus aureus

and interpreted using the CLSI zone diameter interpretative standard 2015.

\section{Results}

\subsection{Antibacterial Activity of Frond Extract}

Antibacterial activity of the three extracts i.e., ethyl acetate, methanol and water of Angiopterishelferiana,
Cyathea brunoniana and Pronephrium nudatum were tested against three multi drug resistant organisms viz. Escherichia coli, Pseudomonas aeruginosa and Staphylococcus aureus as well as against standard ATCC strains. The ethyl acetate extract of Cyathea brunoniana and Pronephrium nudatum were found active against methicillin resistant Staphylococcus aureus as well as against Staphylococcus aureus ATCC 25923 (Table 1), where as that of Angiopteris helferiana showed inhibition zone only against 
Staphylococcus aureus ATCC 25923. But, methanol and water extract of any of the plants did not form inhibition zone against the tested micro-organisms.

\subsection{Minimum Inhibitory Concentration}

The minimum inhibitory concentration of Cyathea brunoniana and Pseudomonas aeruginosa was found to be $400 \mathrm{mg} / \mathrm{ml}$ (Table 2).

\subsection{Minimum Bactericidal Concentration}

The minimum bactericidal concentration (Table 3) of the two ferns viz. Cyathea brunoniana and Pronephrium nudatum was found to be $200 \mathrm{mg} / \mathrm{ml}$.

\subsection{Synergistic Activity}

The in vitro synergism of ethyl acetate extract of Cyathea brunoniana and Pronephrium nudatum

Table 2: Minimum inhibitory concentration of ethyl acetate extract of three ferns against Staphylococcus aureus ATCC 25923

\begin{tabular}{|c|c|c|c|c|c|c|}
\hline \multirow{2}{*}{ Ethyl acetate crude extract of fronds } & \multicolumn{7}{|c|}{ Concentrations (mg/ml) } \\
\cline { 2 - 7 } & 25 & 50 & 100 & 200 & 400 & 600 \\
\hline Angiopteris helferiana & + & + & + & + & + & + \\
\hline Cyathea brunoniana & + & + & + & + & - & - \\
\hline Pronephrium nudatum & + & + & + & + & - & - \\
\hline
\end{tabular}

$+=$ Visible formation of growth; - = No visible growth

Table 3: Minimum bactericidal concentration of ethyl acetate extract of three ferns against Staphylococcus aureus ATCC 25923

\begin{tabular}{|c|c|c|c|c|}
\hline \multirow{2}{*}{$\begin{array}{c}\text { Ethyl acetate crude extract of } \\
\text { fronds }\end{array}$} & \multicolumn{4}{|c|}{ Concentrations (mg/ml) } \\
\cline { 2 - 5 } & 200 & 100 & 50 & 25 \\
\hline Angiopteris helferiana & + & + & + & + \\
\hline Cyathea brunoniana & - & + & + & + \\
\hline Pronephrium nudatum & - & - & - & + \\
\hline
\end{tabular}

= Absence of bacterial colony; $\quad+=$ Presence of bacterial colony 


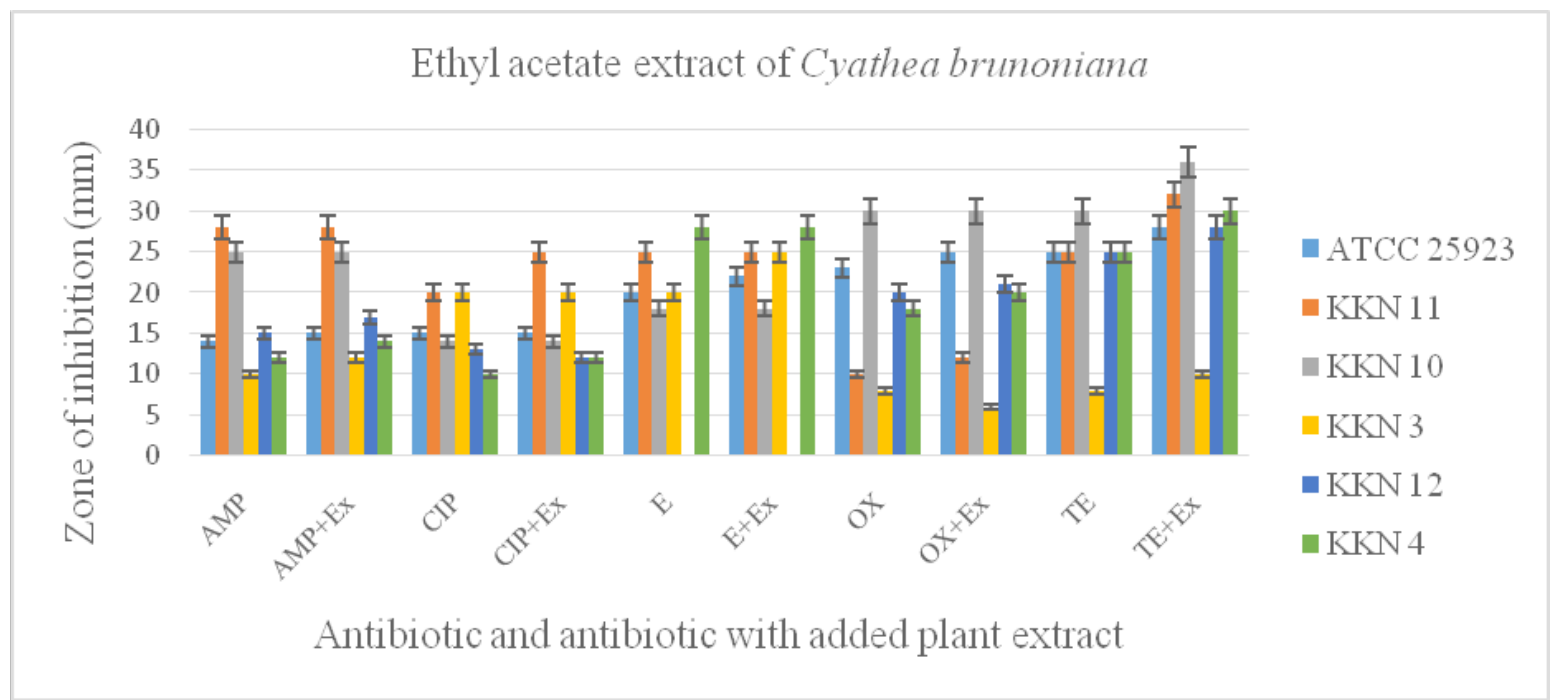

(a)

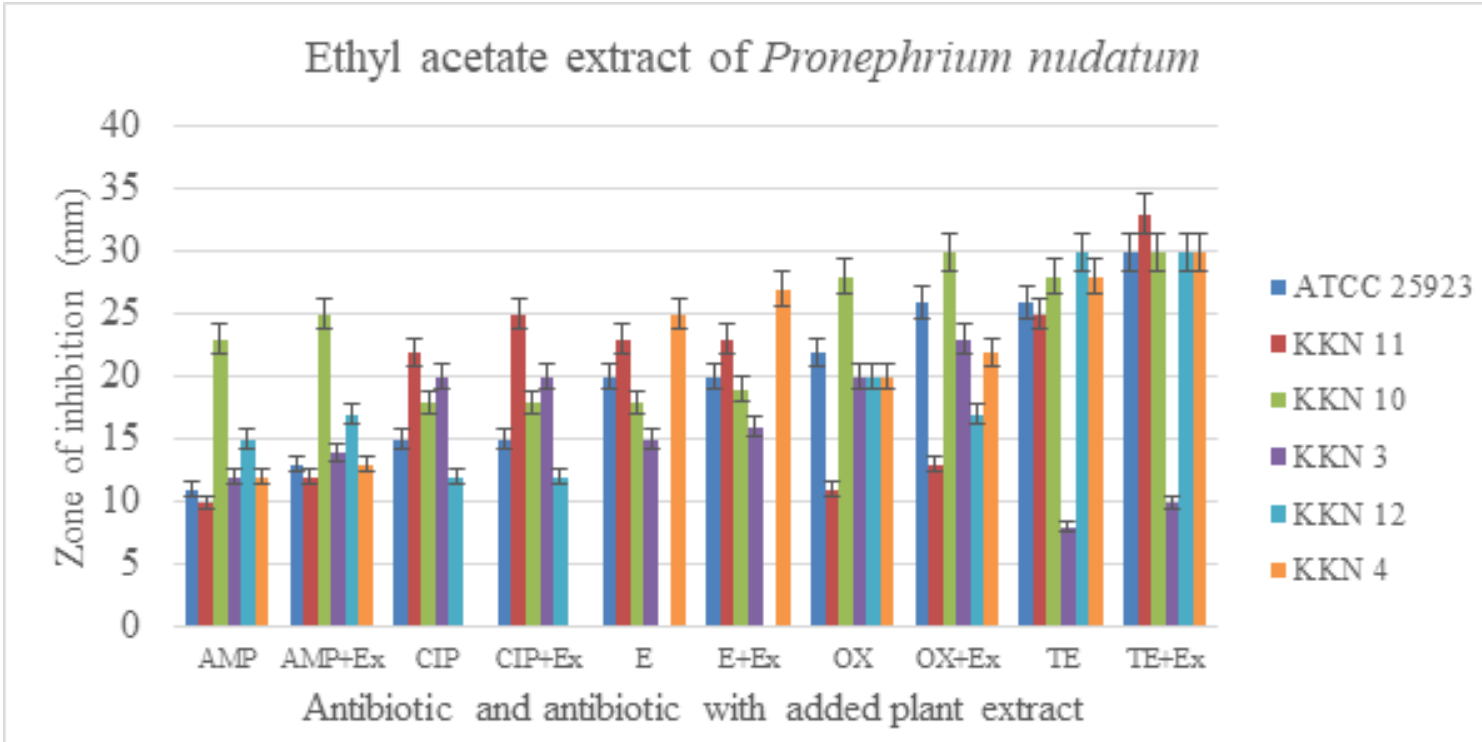

(b)

Fig. 1. Synergistic activity with the ethyl acetate extract of. (a) Cyathea brunoniana. (b) Pronephrium nudatum against methicillin resistant Staphylococcus aureus.

$\mathrm{AMP}=$ Ampicillin; $\mathrm{CIP}=$ Ciprofloxacin $; \mathrm{E}=$ Erythromycin $; \mathrm{OX}=$ Oxacillin; $\mathrm{TE}=$ Tetracyclin; Ex = Extract

with conventional antibiotics against methicillin resistant Staphylococcus aureus (Figure 1 and Figure 2) as well as standard strain Staphylococcus aureus
ATCC 25923 revealed that the antibacterial activity of the antibiotics increased in synergy with the fern's extract. 


\section{Conclusion}

Many naturally occurring compounds found in plants have been shown to possess antimicrobial activities and serve as a source of antimicrobial agents against pathogen ${ }^{16}$. Pteridophytes, the first vascular land plants have also been illustrated for the presence of antimicrobial substances ${ }^{17}$ against a number of pathogenic bacteria and is mainly due to the presence of various secondary phytochemicals viz. alkaloids, terpenoids, flavanoids and others ${ }^{18}$.

The manifestation of new infectious diseases, increase in pathogen resistance and renaissance of several infections is encouraging researchers at both national and international levels towards the development of novel antimicrobial agent. Thus, in the present study an attempt has been made to study the antibacterial activity of crude extract of three ferns viz. Angiopteris helferiana, Cyathea brunoniana and Pronephrium nudatum against three multi drug resistant organisms i.e., Escherichia coli, Pseudomonas aeruginosa and Staphylococcus aureus. The determination of plant material for this study depended on ethno-plant information on the conventional utilization of the plants in treatment of bacterial illnesses, and conditions grouped by the customary healers as "infection" and "inflammation", the latter characterized by reddening (e.g. in wounds), or internal afflictions causing gastric discomfort.

Angiopteris helferiana is of immense ethnomedicinal importance as reported by many authors ${ }^{19,20}$. Paste obtained from young apex of caudex is applied externally over the cuts and wounds for prevention of growth of microbes an also for drying up of wounds ${ }^{11}$. The stem and rhizome are effective in indigestion and bowel, while the bark is used in dysentery and hair loss of cattles ${ }^{19}$. In the present study three solvent extract using the frond of the plant was prepared and tested against both Gram positive and Gram negative organisms of multi drug resistant strain as well as standard strain ATCC. The result revealed that the ethyl acetate extract was only active against Staphylococcus aureus standard strain ATCC 25923. The minimum inhibitory assay was also carried out but could be determined as because growth of organisms were visible even at the highest dilution i.e., $600 \mathrm{mg} / \mathrm{ml}$ used during the experiment. The result of present study supports the traditional use of the fern in preventing microbial infection.

The apical soft portion of the caudex of Cyathea brunoniana possesses ethno-medicinal importance, which is being used on major cuts and wounds to prevent microbial growth ${ }^{10}$. The qualitative phytochemical screening of ethyl acetate frond extract of Cyathea brunoniana revealed the presence of flavanoid, steroid, saponnin ${ }^{12}$. The crude ethyl acetate frond extract of Cyathea brunoniana when tested against both Gram positive (Staphylococcus aureus) and Gram negative (Escherichia coli, Pseudomonas aeruginosa) multi drug resistant organisms, was found effective only against methicillin resistant Staphylococcus aureus (Table 1) with minimum inhibitory concentration 
of $400 \mathrm{mg} / \mathrm{ml}$ (Table 2). This antibacterial activity of the plant may be due to the presence of flavonoid and steroid as flavanoids are known to be synthesised by plants in response to microbial infection $^{21}$ whereas steroids have been found to possess antimicrobial property ${ }^{22}$. The inhibition zone of the tested conventional antibiotics used for treating Staphylococcal infection has increased may be due to the synergistic effects resulting from the combination of the antibiotics and the crude ethyl acetate extract (Figure 1 and Figure 2). The resent report provide an important basis for the use of ethyl acetate extract of the fern for use against Gram positive especially Staphylococcus aureus infections including MRSA.

Pronephrium nudatum an ethno-medicinally imperative fern, used for the treatment of pyorrhoea ${ }^{10}$, 23. It has been seen in the present experiment that of the three extracts i.e., ethyl acetate, methanol and water, crude ethyl acetate frond of the fern was acreus (Table 1) with minimum inhibitory concentration of $400 \mathrm{mg} / \mathrm{ml}$ (Table 2). The present result may be validated by the antifungal activity of the plant against Aspergillus niger ${ }^{24}$. Increased activities of the antibiotics, which are used in Staphylococcal infection, were observed resulting from the synergistic effect of antibiotic and crude extract (Figure 1). tive against methicillin resistant Staphylococcus au-

activity especially against methicillin resistant Staphylococcus aureus as well as standard strain Staphylococcus aureus ATCC 25923. However, ethyl acetate extract of Angiopteris helferiana was active against only Staphylococcus aureus ATCC 25923.

Thus the ethyl acetate extract of Cyathea brunoniana and Pronephrium nudatum may be used against Staphylococcal infection consequently providing a future treatment option against methicillin resistant Staphylococcus aureus. But, further isolation and identification of specific antimicrobial compounds from crude ethyl acetate extract of Cyathea brunoniana and Pronephrium nudatum can pave better ways to control Staphylococcal infections and also to find a novel approach to grab the emergence of drug resistant specially methicillin resistant strains of Staphylococcus aureus.

\section{Acknowledgements}

The authors acknowledge the Department of Microbiology, Assam University for providing the infra-structure facility and also Assam University Biotech Hub and Karimganj College Biotech Hub for providing laboratory facility to complete this work.

\section{References}

\section{Conclusion}

From the present study it is evident that the crude ethyl acetate extract of Cyathea brunoniana and Pronephrium nudatum possesses antibacterial
1. Hancock EW. Mechanisms of action of newer antibiotics for gram positive pathogens. Lancet Infect Dis. 2005; 5:209-18. Available from: http://www.sciencedirect.com/science/article/pii/S1473309905700517. Crossref. 
2. Benhassaini H, Enabderrahmane K, Chi K. Contribution to the assessment of the antiseptic activity of essential oils and oleoresin of Pistaciatial Atlas on some microbial sources: Candida albicans (ATCC 20027), Candida albicans (ATCC 20032) and Saccharomyces cerevisiae. Ethnopharmacology. 2003; 30:38-46.

3. Dahiya P, Purkayastha S. Phytochemical screening and antimicrobial activities of some medicinal plants against multi-drug resistant bacteria from clinical isolates. Indian Journal of Pharmaceutical Sciences. 2012; 74(5):443-50. Available from: https:// www.ncbi.nlm.nih.gov/pmc/articles/PMC3660871/. Crossref. PMid:23716873 PMCid:PMC3660871

4. Fraser-Jenkins CR. Three hundred Indian subcontinental pteridophytes with a revised census list. Dehradun, India: Bishen Singh Mahendra Pal Singh; 2008.

5. Dixit RD. Fern- A much neglected group of medicinal plants. I. J Res Indian Med. 1974; 9:74-90.

6. Rao KT, Reddy RN, Pattanaik C, Reddy S. Ethnomedicinal importance of Pteridophtes used by Chenchus of nallamalais, Anhra Pradesh, India. Ethnobotanical Leaflets. 2007; 11:6-10.

7. Perumal G. Ethnomedicinal use of pteridophyte from Kolli Hills, Namakkal District, Tamil Nadu, India. Ethnobotanical Leaflets. 2010; 14:161-72.

8. Kholia BS, Punetha N. Useful peridophytes of kumaon (Central Himalaya, India). Indian Fern Journal. 2005; 22:1-6.

9. Mathew PJ, Remesh M, Kumar M. Ethnobotanical studies on wild leafy vegetables used by two tribals groups of Attappady Palakkad. National seminar on plant Biodiversity Systematics Conservation and Ethnobotany; Siliguri, West Bengal. 2000.

10. Shil S, Choudhury MD. Ethnomedicinal importance of Pteridophytes used by Reang tribe of Tripura, North East India. Ethnobotanical Leaflets. 2009; 13:634-43.
11. Choudhury MD, Das B, Mazumder PB. Fern flora and fern allies of southern assam- ethno-medico botanical studies and certain conservation aspects. Udaipur, India: Scichem Publishing House; 2009.

12. Talukdar AD, Choudhury MD, Chakraborty M, Dutta BK. Phytochemical screening and TLC profiling of plant extracts of Cyathea gigantea (Wall. Ex. Hook.) Haltt. and Cyathea brunoniana. Wall. ex. Hook. (Cl. \&Bak.). Assam University Journal of Science and Technology: Biological and Environmental Sciences. 2010; 5:70-4.

13. Bobbarala VV, Katikala PK, Naidu KC, Penumajji S. Antifungal activity of selected plant extracts against phytopathogenic fungi Aspergillus niger F2723. Indian J Sci Technol. 2009; 2:6839-46.

14. Thomas T. Priliminary antibacterial evaluation of fronds of Pterisquadriaurita Retz towards bacterial involved in dermatological diseases. Journal of Applied Pharmaceutical Science. 2011; 1(8):214-6.

15. Rotimi, VO, Laughon BE, Barlet JS, Mosadomi HA. Activities of Nigerian chewing sticks extracts against Bacterioidesgingivalis and Bacterioidesmelaninogenicus. Antimicrob. Agents Chemother. 1988; 32:598-600. Crossref.

16. Kumar V, Neelam S, Padh H, Rajani M. Search for antibacterial and antifungal agents from selected medicinal plants. Journal of Ethnopharmacology. 2006; 107:182-8. Crossref. PMid:16678369

17. Sen S, Nandi P. Antibiotics from the pteridophytes. Sci Cult. 1951; 16:328-9.

18. Cowan MM. Plant products as antimicrobial agents. Clin Microbiol Rev. 1999; 12(4):564-82. PMid:10515903 PMCid:PMC88925

19. Singh BP, Upadhyay R. Ethno-botanical importance of Pteridophytes used by the tribe of Pachmarhi, Central India. Journal of Medicinal Plants Research. 2012; 6(1):14-8.

20. Upadhyay R, Singh BP, Upadhyay ST. Ethno-medicinal observations on a threatened tree fern, Cyathea 
spinilosa Wall. Ex Hook in Satpura hills. Indian Fern Journal. 2011; 28:129-36.

21. Dixon R, Dey P, Lamb C. Phytoalexins: Enzymology and molecular biology. AdvEnzymol. 1983; 55:1-69. Crossref.

22. Chattopadhyay D, Maiti K, Kundu AP, Chakraborty MS, Bhadra R, Maudal SC, Maudal, AB. Antimicrobial activity of Alstoniamacrophylla: A folklore of bay islands. J Ethnopharmacol. 2001; 77:49-55. Crossref.
23. Singh BP, Upadhyay R. Medicinal Pteridophytes of Madhya Pradesh. Journal of Medicinal Plants Studies. 2014 ; 2(4):65-8.

24. Goswami HK, Sen K, Mukhopadhyay R. Pteridophytes: Evolutionary boon as medicinal plants. Plant Genetic Resources. 2016; 14(4):328-55.Crossref.

25. Clinical and laboratory standards institute. Performance standards for antimicrobial susceptibility testing 25th Informational Supplement M100-S24. Wayne, PA, USA: CLSI; 2015. 